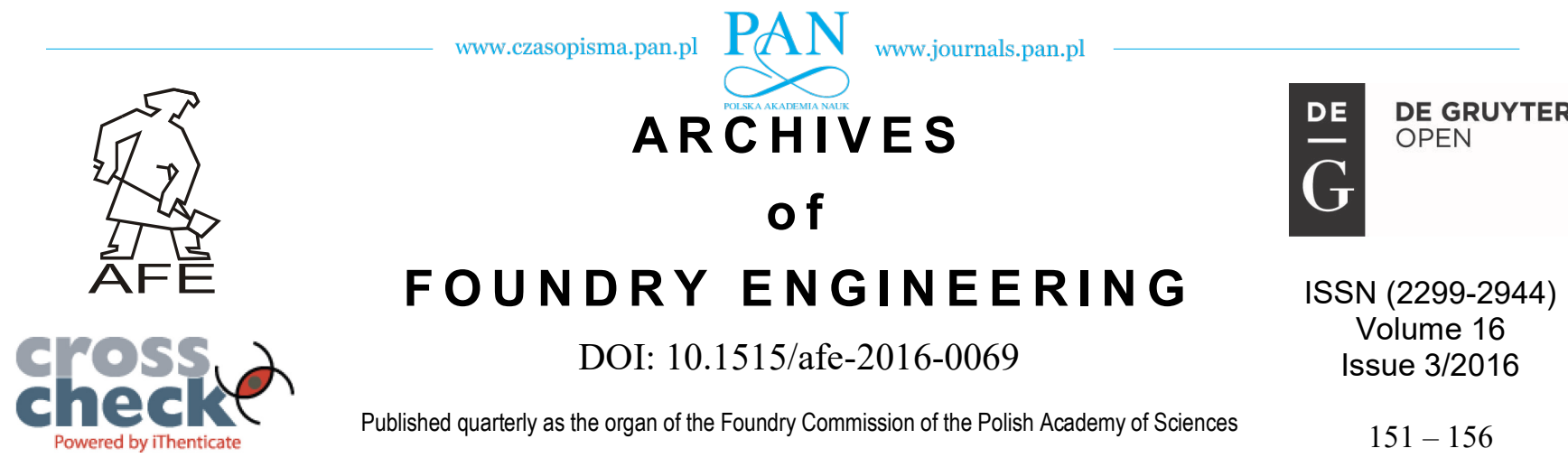

\title{
Quality Evaluation of Remelted A356 Scraps
}

\author{
C. Yuksel ${ }^{\text {a }}$, O. Tamer ${ }^{\text {a }}$, E. Erzi ${ }^{\text {b }}$, U. Aybarc ${ }^{\text {c }}$, E. Cubuklusu ${ }^{\text {c }}$, O. Topcuoglu ${ }^{\text {c }}$, M. Cigdem ${ }^{\text {a }}$, D. Dispinar ${ }^{\text {b* }}$ \\ ${ }^{a}$ Yildiz Technical University, Turkey \\ ${ }^{\mathrm{b}}$ Istanbul University, Turkey \\ ${ }^{\mathrm{c}}$ CMS Izmir, Turkey \\ *Corresponding author. E-mail address: deryad@istanbul.edu.tr
}

Received 10.12.2015; accepted in revised form 29.02.2016

\begin{abstract}
A356 is one of the widely used aluminium casting alloy that has been used in both sand and die casting processes. Large amounts of scrap metal can be generated from the runner systems and feeders. In addition, chips are generated in the machined parts. The surface area with regard to weight of chips is so high that it makes these scraps difficult to melt. Although there are several techniques evolved to remedy this problem, yet the problem lies in the quality of the recycled raw material. Since recycling of these scrap is quite important due to the advantages like energy saving and cost reduction in the final product, in this work, the recycling efficiency and casting quality were investigated. Three types of charges were prepared for casting: \%100 primary ingot, $\% 100$ scrap aluminium and fifty-fifty scrap aluminium and primary ingot mixture were used. Melt quality was determined by calculating bifilm index by using reduced pressure test. Tensile test samples were produced by casting both from sand and die moulds. Relationship between bifilm index and tensile strength were determined as an indication of correlation of melt quality. It was found that untreated chips decrease the casting quality significantly. Therefore, prior to charging the chips into the furnace for melting, a series of cleaning processes has to be used in order to achieve good quality products.
\end{abstract}

Keywords: Bifilm index, Melt quality, Scrap, Recycle, Mechanical properties

\section{Introduction}

The foundry industry has always focused on factors affecting the properties of aluminium and its alloys. Most of the work was based on porosity and its effect over the mechanical properties. Therefore, many researchers investigated the formation of pores during casting [1-6]. The main source of porosity in aluminium castings was blamed to be hydrogen which has a high solubility in liquid but very low in solid. Thus, it is proposed that the rejected hydrogen from the growing dendrites is accumulated between the secondary arms to nucleate and form porosity. On the other hand, Campbell et al. [7-10] have shown the effects of surface entrained defects (i.e. bifilms) and their relation with porosity.

Bifilm which can be formed during the turbulent flow or transfer of the melt in a casting process can be found in the final microstructure and reduce the service life of cast part. Therefore, controlling the quality of the cast part begins with quality of melt. The starting materials bifilm content has to be as low as possible. Dispinar [11-19] has carried out an extensive study to be able to numerically measure the quality of a melt and proposed an index called bifilm index [16].

If bifilm are trapped by surface turbulence during the casting process, they become crumpled and smaller in size. When the sizes are between 0.1-1.0 $\mathrm{mm}$ diameter, bifilms are quite dangerous. They can be in the form of a straight crack and freeze in the cast part as a big crack in the microstructure. However, they may increase their harmful effect 10 times when they start to unravel. There are several mechanisms that can open (unravel) bifilms to form a crack [2]; 
(i) precipitation of the hydrogen into the air layer between the films,

(ii) shrinkage (effect of reducing pressure on films),

(iii) precipitates between iron (beta phase form) and other metals (intermetallic),

(iv) coarse grain size

It is "known" that hydrogen porosity, shrinkage porosity, iron levels and coarse grain size reduces ductility. However, these socalled sources are actually all initiated by bifilms. Therefore, its neither hydrogen, nor shrinkage or the iron level, but the unravelling or stretching of the folded bifilms that causes a decrease in ductility $[12,14,19-21]$. Therefore, bifilms are the most important factor to control the mechanical properties of cast part. The simplest way of quantifying bifilms in the melt is the use of solidification test under vacuum. The sectioned surface of the samples can be processed by image analysis software to measure the maximum length of pores as an indication of total oxide length; i.e. bifilm index [16]:

$$
\text { Bifilm Index }=\sum(\text { Pore Length })=L_{b}
$$

This index is a value measured in millimetres and it is simple and can be easily in the industry as an evaluation of melt quality.

Dispinar et al. [30] and Kvithyld et al. [31] had studied the recycling efficiency of coated sheets and concluded that the removal of the surface contaminations increased the yield to around $97 \%$ prior to melting.

Hatayama et al. [22] discuss the Material Flow Analysis (MFA) techniques to predict the scrap sorting and recycling potential of aluminium and its alloys. It was concluded that the primary alloy usage could be lowered as much as $25 \%$. Modaresi and Muller [23] predicts that by 2050 , the energy saving potential is around
43-240 TWh/year if all the aluminum alloys are recycled from vehicles. However, it was indicated that the difficulties in refining process of scrap leads to the strategies where primary alloy supply is prefered. Similar calculations were also made by Cullen [24] and Lovik et al. [25]. Gaustad et al. [26] has reviewed the techniques of removing unwanted elements and general recycling issues. Lately, recycling by hot extrusion pressing has been very popular [26-29].

In this work, the recycled melt quality was measured by bifilm index and its correlation with the mechanical properties were determined.

\section{Experimental study}

Primary ingot and turnings of aluminium alloy A356 from a wheel producer were used in the tests. The chemical composition of A356 aluminium alloy are given in Table 1.

Table. 1.

The chemical composition of A356 aluminium alloy

\begin{tabular}{ccccccc}
\hline $\mathrm{Si}$ & $\mathrm{Mg}$ & $\mathrm{Cu}$ & $\mathrm{Fe}$ & $\mathrm{Mn}$ & $\mathrm{Ti}$ & $\mathrm{Al}$ \\
\hline 7.13 & 0.389 & 0.023 & 0.135 & 0.002 & 0.114 & Rem. \\
\hline
\end{tabular}

In the experimental work, three different combinations of charge material were used:
i) $\quad 100 \%$ primary ingot,
ii) $\quad 50 \%$ primary ingot $+50 \%$ chip
iii) $\quad 100 \%$ chip

The ingot and chips used in the study is shown in Figure 1. a)

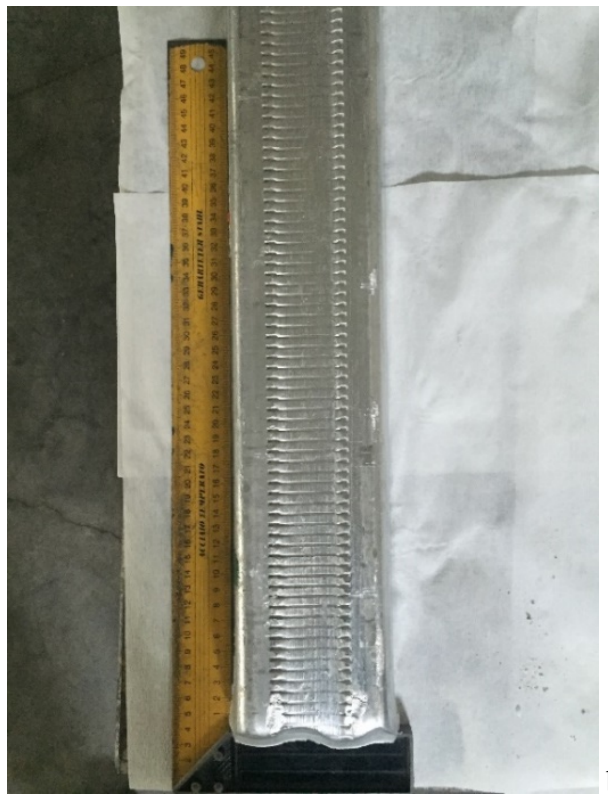

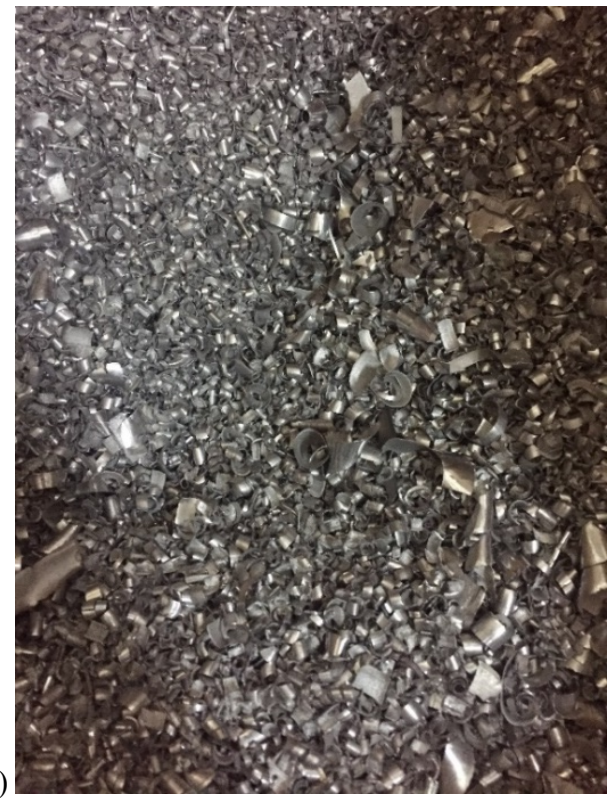

Fig. 1. (a) primary ingot (b) chips 
$20 \mathrm{~kg}$ silica sand, $1 \mathrm{~kg}$ of bentonite and $0.66 \mathrm{~kg}$ water were mixed with the help of sand mixer machine and moulds were produced

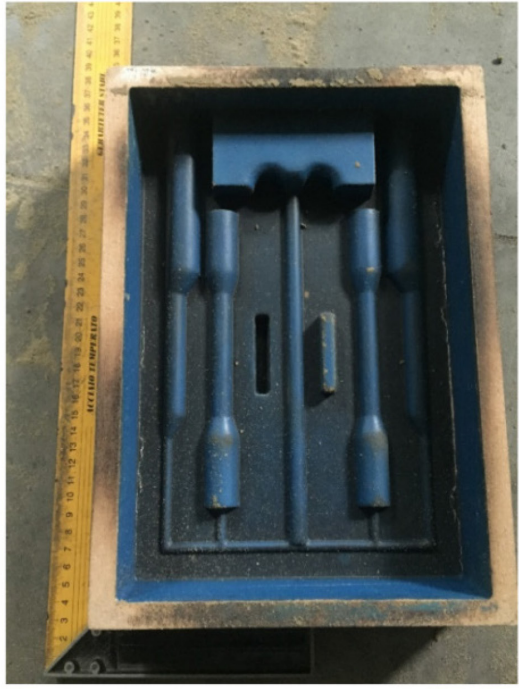

(a) as seen in Figure 2.

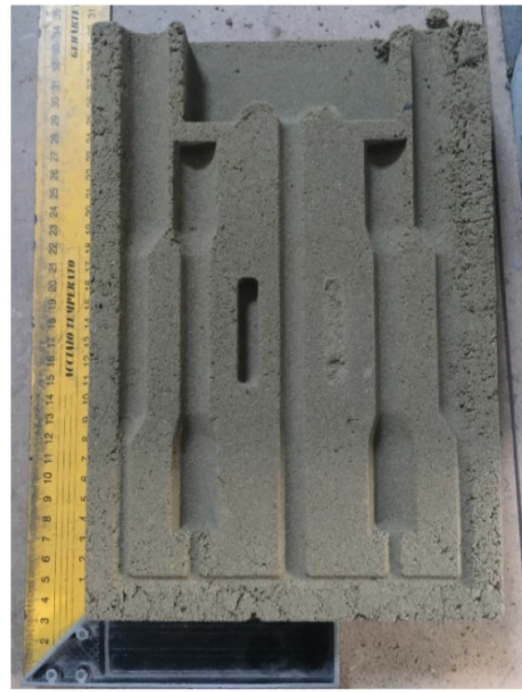

(b)

Fig. 2. The two bar (a) pattern and (b) sand mould

Melting process was made with $50 \mathrm{~kW}$ induction furnace. A charge of $4 \mathrm{~kg}$ was prepared in each casting process. In order to achieve $50-50 \%$ mixture, $2 \mathrm{~kg}$ of primary ingot and $2 \mathrm{~kg}$ of chip were used. The casting temperature in each of the tests were kept constant as $740{ }^{\circ} \mathrm{C}$. Melt temperature was measured continuously by K-type thermocouple. Reduced Pressure Test (RPT) samples were taken at certain time intervals and simultaneously two tensile test bars were cast. The mould used in RPT tests has conical geometry wit base diameter of $40 \mathrm{~mm}, 20 \mathrm{~mm}$ height and $70 \mathrm{~mm}$ top diameter. RPT samples were then sectioned (Fig 3) and SigmaScanPro software was used to measure bifilm index. Mohr-Federhaff 10-ton tensile machine was used to examine the tensile strength of the materials used in this work by ASTM E-800 standards. The diameter of the tensile test bars was $12 \mathrm{~mm}$ in neck and $20 \mathrm{~mm}$ in grips with $75 \mathrm{~mm}$ length for the extensometer grips (Fig 2).

\section{Results and discussion}

The cross section of the reduced pressure test samples is given in Figure 3. As can be clearly seen (Fig 3c), the primary alloy has almost no visible pores. On the other hand, as the chip ratio was increased, there was a significant increase in both the number and the size of the pores. a)

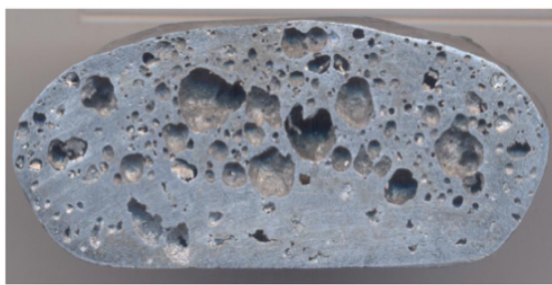

b)

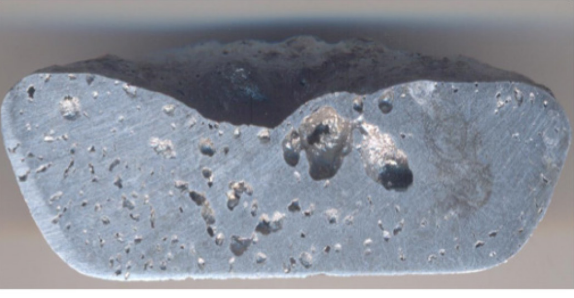

c)

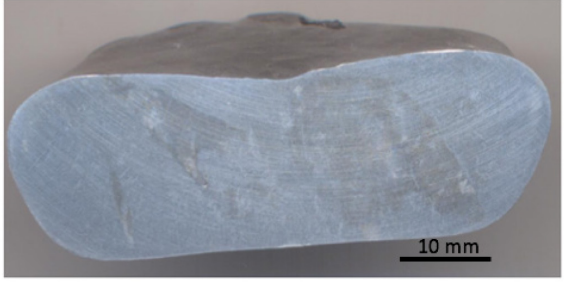

Fig. 3. RPT samples collected from the melt for conditions:

(a) $\% 100$ chip (b) $\% 50$ primary ingot - $\% 50$ chip (c) $\% 100$ primary ingot 
Figure 4 is show a comparative chart which has different cast melt conditions and Bifilm Index. As can be seen from this graph that $100 \%$ primary ingot which has a $5.8 \mathrm{~mm}$ bifilm index is the cleanest melt and $100 \%$ chip which has $221.5 \mathrm{~mm}$ bifilm index is the lowest quality melt. $50-50 \%$ mixture melt has a bifilm index of $95 \mathrm{~mm}$. One of the important observations was the increase of scatter of results as the content of the chips (i.e. scrap) was increased (Fig 4). Dispinar et al. [16-18] had suggested in their earlier work that higher the scatter of the bifilm index incidated higher population of bifilms in the melt. The surface area to weight ratio of chips are so high (Fig 1b). It is well known that one of the most important features of the aluminium alloy is its protective oxide on the surface. Thus, as the chips were melted, the surfaces of the chips that were in contact with each other (Fig 1b) has automatically been introduced into the melt as bifilms. This is the main reason why the number and the sizes of pores are so scattered in the cross section of RPT samples in Fig $3 \mathrm{a}$ and $b$.

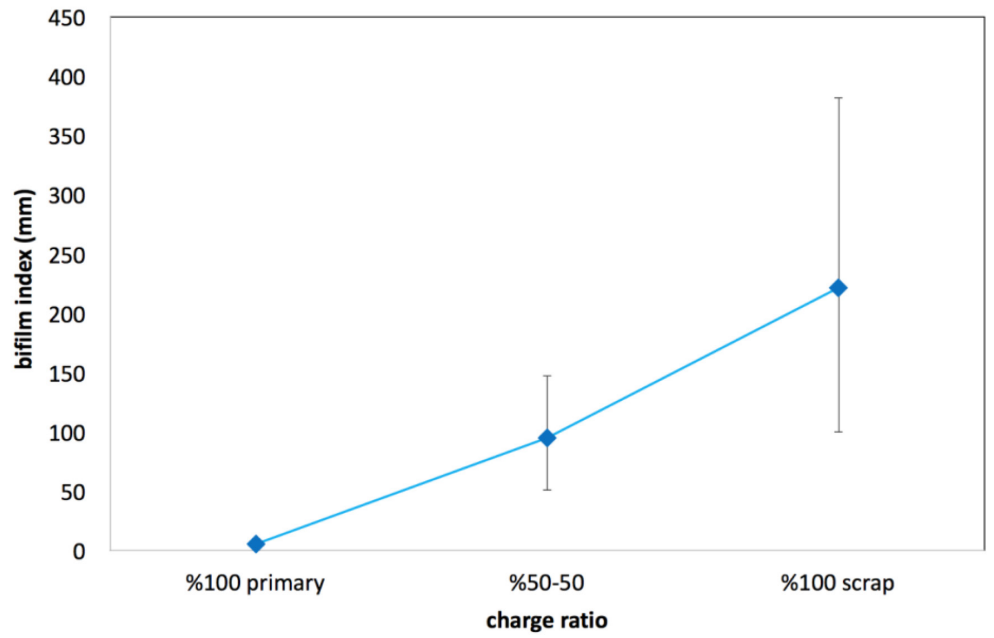

Fig. 4. Bifilm index of different charges

Figure 5 shows the bubble diagram of the mechanical test results. It can be seen that the scatter of the test results (i.e. bubble size) were almost similar in all conditions. The primary alloy properties were the highest amongst the conditions tested in this work: it lies on the right top corner of the plot which indicates that the ultimate tensile strength and the elongation at fracture was the highest.

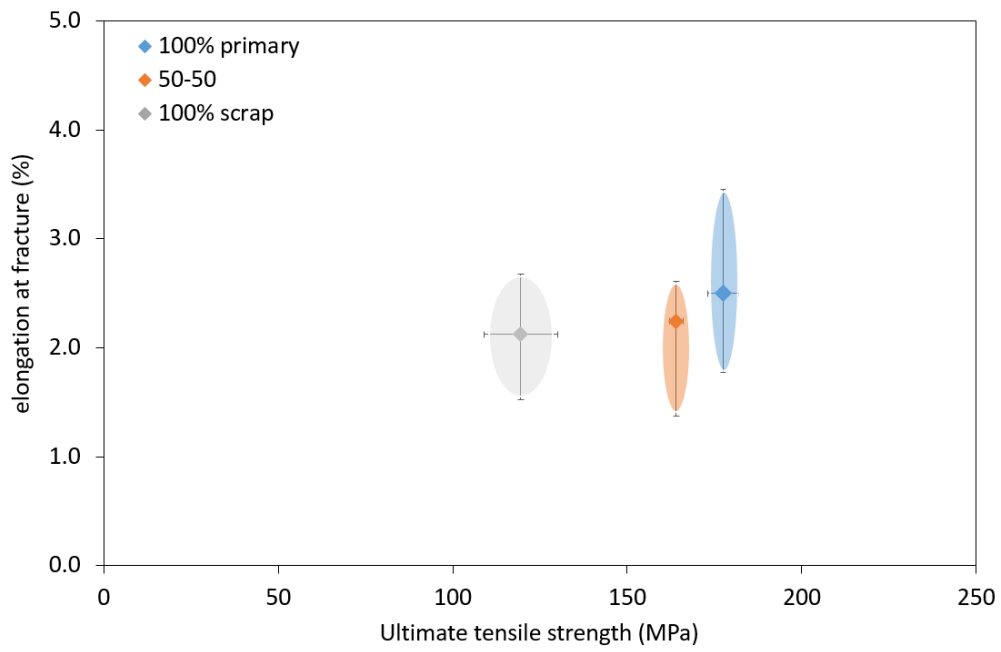

Fig. 5. Bubble diagram of the tensile test results

When tensile properties of all three conditions are compared, there was an interesting observation. As seen in the bubble diagram in Fig 5, as the scrap ratio was increased, ultimate tensile strength decreased (the $\mathrm{x}$-axis values). However, elongation at fracture values for $100 \%$ scrap and $50-50 \%$ mixture appears to be very close around $2.3 \%$. This relationship was also evaluated by means of using bifilm index as seen in Figure 6. Ultimate tensile strength was decreasing linearly with increased bifilm index. Thus, it can be concluded that as the quality of the melt is lowered, the mechanical properties decrease. Yusuf [29] had 
found similar results. It was found that the strength of the recycled samples was decreased. Ludwig et al. [6] found that there was an average of $10 \%$ decrease in the mechanical properties with the

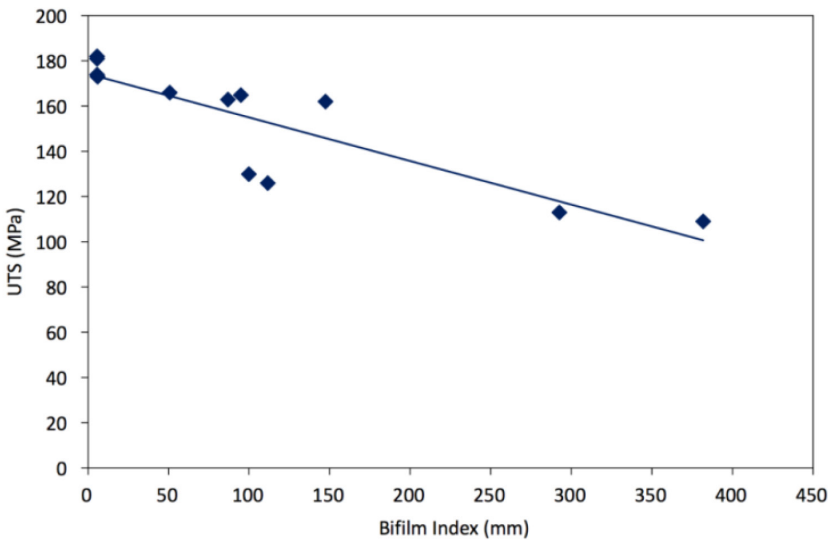

a) increased oxide content where oxides were both measured by bifilm index and PoDFA.

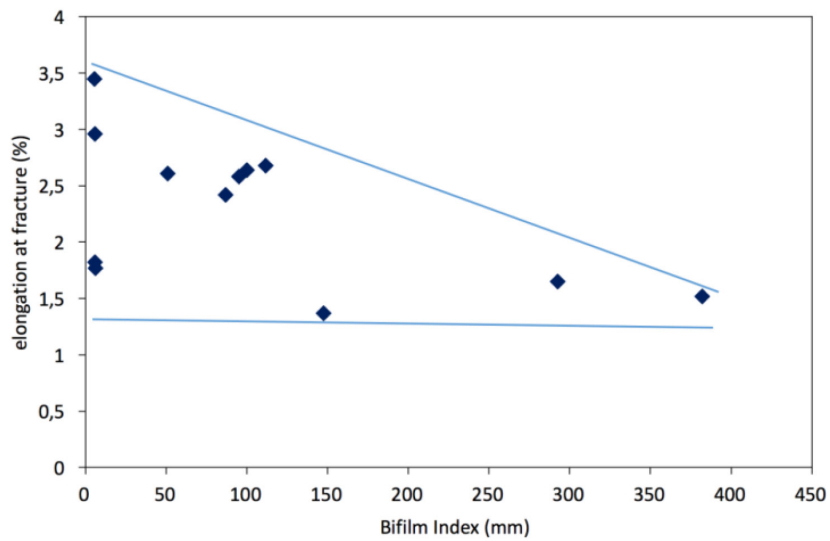

b)

Fig. 6. The correlation between mechanical properties with bifilm index

(a) UTS, (b) elongation at fracture

As seen in Figure 6a, the correlation between bifilm index and tensile strength is close to linear. It can be easily concluded that as the bifilm index was increased UTS was decreased. On the other hand, this was not the case with the elongation at fracture values. When the maximum and the minimum values are connected as straight lines, the bottom values form a horizontal line and the top values form a linear line (Figure 6b). And this result appears as the bifilm index is increased, elongation at fracture values certainly decrease. However, when the bifilm index is low (i.e. high quality melt), it does not necessarily mean that the toughness will be high, too. Campbell [2] had shown the effect of reduction in area by the presence of a defect and how it would effect the elongation at fracture in Figure 7. In the same analogy, considering a bifilm with a size of $1 \mathrm{~mm}$, its orientation with reference to the tensile axis has to play an important role for the determination of the elongation at facture. If it lies parallel with the tensile axis, the elongation at fracture might be high. On the contrary, the positioning of the same size bifilm perpendicular to the axis has to decrease the elongation at fracture at a relatively lower value. Dispinar [12-14] had found similar results. It can be concluded that as the bifilm index was increased (low quality melt): the higher the population of these defect, the most likely the material will fail easily.

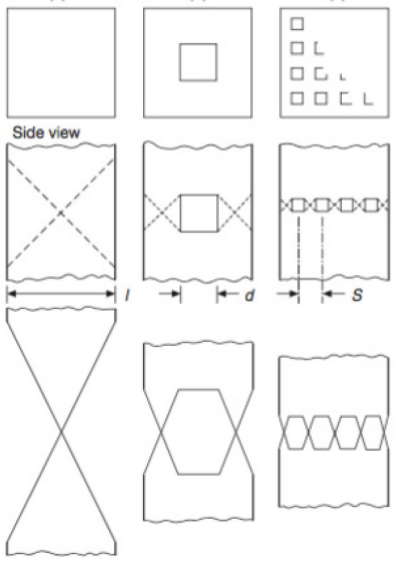

Fig. 7. Simple ductile failure model [2]

Hatayama [22] proposed that primary aluminium requirement can be reduced by $25 \%$ by correct scrap sorting. In this work, the basis for the achievement of high quality casting from scraps has been investigated. Thus, it is expected that this ratio can even be extended to higher levels by proper measurement of the melt quality.

\section{Conclusions}

1. Reduced pressure test can quantitatively give an indication of the melt quality of aluminium alloys by using bifilm index.

2. There is a linear relationship between mechanical properties and bifilm index.

3. As the scrap ratio in the melt is increased, the quality decreases linearly.

4. Quality of the melt can be increased by controlled treatment of the scrap and proper cleaning process prior to charging. 


\section{Acknowledgements}

This publication was supported by TUBITAK (Project No.: 114M100) and partially by SANTEZ 0802.STZ2014. We would like to show our gratitude to CMS Wheels of Industry for supply of chips and ingots.

\section{References}

[1] Akhtar, S., et al. (2009). Effect of hydrogen content, melt cleanliness and solidification conditions on tensile properties of A356 alloy. International Journal of Cast Metals Research. 22(1-4), 22-25.

[2] Campbell, J. (2011). Complete casting handbook: metal casting processes, techniques and design. ButterworthHeinemann.

[3] Hsu, F.-Y., M.R. Jolly, Campbell, J. The Design of L-Shaped Runners for Gravity Casting. in Metals \& Materials Society The Minerals, Proceedings of Shape Casting: 2nd International Symposium, Orlando, FL, USA. 2007.

[4] Hsu, F.-Y., Jolly M.R. \& Campbell, J. (2009). A multiplegate runner system for gravity casting. Journal of Materials Processing Technology. 209(17), 5736-5750.

[5] Li, D., Campbell, J. \& Li, Y. (2004). Filling system for investment cast Ni-base turbine blades. Journal of Materials Processing Technology. 148(3), 310-316.

[6] Ludwig, T.H., et al., (2012). Influence of oxide additions on the porosity development and mechanical properties of A356 aluminium alloy castings. International Journal of Metalcasting. (6), 41-50.

[7] Campbell, J. (2000). The concept of net shape for castings. Materials \& Design. 21(4), 373-380.

[8] Campbell, J. (2006). An overview of the effects of bifilms on the structure and properties of cast alloys. Metallurgical and Materials Transactions B. 37(6), 857-863.

[9] Campbell, J. (2011). The origin of Griffith cracks. Metallurgical and Materials Transactions B. 42(6). 10911097.

[10] Campbell, J. (2015). Sixty Years of Casting Research. Metallurgical and Materials Transactions A. 46(11), 48484853.

[11] Di Sabatino, M., et al., (2009). A Comparative Study Of Porosity And Pore Morphology In A Directionally Solidified A356 Alloy. International Journal of Metalcasting. 3(1).

[12] Dispinar, D., et al., (2010). Degassing, hydrogen and porosity phenomena in A356. Materials Science and Engineering: A. 527(16), 3719-3725.

[13] Dispinar, D., et al. (2012). Correlation between Mechanical Properties and Porosity Distribution of A356 in Gravity Die Casting and Low Pressure Die Casting. in Advanced Materials Research. Trans Tech Publ.

[14] Dispinar, D., et al. (2012). Tensile Properties, Porosity and Melt Quality Relation of A356. Supplemental Proceedings: Materials Properties, Characterization, and Modeling. 2, 201-208.
[15] Dispinar, D. \& Campbell, J. (2004). Critical assessment of reduced pressure test. Part 1: Porosity phenomena. International Journal of Cast Metals Research. 17(5), 280286.

[16] Dispinar, D. \& Campbell, J. (2004). Critical assessment of reduced pressure test. Part 2: Quantification. International Journal of Cast Metals Research. 17(5), 287-294.

[17] Dispinar, D. \& Campbell, J. (2006). Use of bifilm index as an assessment of liquid metal quality. International Journal of Cast Metals Research. 19(1), 5-17.

[18] Dispinar, D. \& Campbell, J. (2007). Effect of casting conditions on aluminium metal quality. Journal of Materials Processing Technology. 182(1), 405-410.

[19] Dispinar, D. \& Campbell, J. (2011). Porosity, hydrogen and bifilm content in Al alloy castings. Materials Science and Engineering: A. 528(10), 3860-3865.

[20] Tiryakioğlu, M. \& Campbell, J. (2009). Ductility, structural quality, and fracture toughness of $\mathrm{Al}-\mathrm{Cu}-\mathrm{Mg}-\mathrm{Ag}$ (A201) alloy castings. Materials Science and Technology. 25(6), 784-789.

[21] Tiryakioğlu, M., Campbell, J. \& Alexopoulos, N.D. (2009). On the ductility of cast Al-7 pct Si-Mg alloys. Metallurgical and Materials Transactions A. 40(4), 1000-1007.

[22] Hatayama, H., et al., (2012). Evolution of aluminum recycling initiated by the introduction of next-generation vehicles and scrap sorting technology. Resources, Conservation and Recycling. 66, 8-14.

[23] Modaresi, R. \& Müller, D.B. (2012). The role of automobiles for the future of aluminum recycling. Environmental Science \& Technology. 46(16), 8587-8594.

[24] Cullen, J.M. \& Allwood, J.M. (2013). Mapping the global flow of aluminum: From liquid aluminum to end-use goods. Environmental Science \& Technology. 47(7), 3057-3064.

[25] Løvik, A.N., Modaresi, R. \& Müller, D.B. (2014). LongTerm Strategies for Increased Recycling of Automotive Aluminum and Its Alloying Elements. Environmental Science \& Technology. 48(8), 4257-4265.

[26] Gaustad, G., Olivetti, E. \& Kirchain, R. (2012). Improving aluminum recycling: A survey of sorting and impurity removal technologies. Resources, Conservation and Recycling. 58, 79-87.

[27] Ab Rahim, S., Lajis, M. \& Ariffin S. (2015). A Review on Recycling Aluminum Chips by Hot Extrusion Process. Procedia CIRP. 26, 761-766.

[28] Shahrom, M.S. \& Yusoff. A.R. (2014). Review of Aluminum Chip Machining Using Direct Recycling Process. Advanced Materials Research. Trans Tech Publ.

[29] Yusuf, N.K., et al. (2013). Effect of Operating Temperature on Direct Recycling Aluminium Chips (AA6061) in Hot Press Forging Process. Applied Mechanics and Materials. Trans Tech Publ.

[30] Dispinar, D., Kvithyld, A. \& Nordmark, A. (2011). Quality Assessment of Recycled Aluminium. Light Metals. 731-735.

[31] Kvithyld, A., et al. (2012). Quality Comparison between Molten Metal from remelted Sheets; Mill Finish and Coated. in AIP Conference Proceedings. American Institute of Physics, Ste. 1 NO 1 Melville NY 11747-4502 United States. 